\title{
USO PÚBLICO DA PRAIA DE GRUMARI, RJ: CARACTERIZAÇÃO DOS VISITANTES
}

\author{
Marcos Aurélio Perroni dos Santos ${ }^{1}$ \\ Rita de Cássia Martins Montezuma ${ }^{2}$ \\ Janice Resende Vieira Peixoto ${ }^{3}$
}

\section{RESUMO}

O objetivo do trabalho foi caracterizar o perfil dos visitantes da praia de Grumari, durante o período de agosto de 2015 a julho de 2016. Foi possível identificar o nível de percepção dos usuários sobre a praia, assim como suas preferências e críticas. Para uma análise mais precisa os dados foram segmentados por estações do ano, pois assim, foi possível particularizar, de modo sazonal, o perfil dos visitantes. De um modo geral, o público se mostrou rotineiro, visto que $43 \%$ frequenta a praia mais de dez vezes ao ano, são instruídos e oriundos da Zona Oeste da cidade $(67,50 \%)$. Apresentou ter um conhecimento superficial que a praia estava localizada em uma unidade de conservação $(48,50 \%)$, o tempo médio de permanência foi de 2 a 6 horas, já o tamanho dos grupos foi, majoritariamente, formado por 2 a 4 pessoas (75\%). A principal atividade eleita foi o banho de mar (53\%), sendo o mar a maior atrativo. $\mathrm{O}$ público se mostrou indiferente ou pouco informado sobre os problemas encontrados na praia (38\%), o entendimento sobre a importância da restinga para a praia foi caracterizado como superficial $(40 \%)$. No verão constatou-se que os visitantes são pouco informados, descentralizados regionalmente, com o maior número de pessoas que visitam a praia pela primeira vez e os maiores grupos. No outono foi identificado um público com maior conhecimento sobre a importância da restinga, mais assíduos na visitação, o maior número de pessoas que estão desacompanhadas e os que mais pediram por segurança. $\mathrm{Na}$ estação do inverno foi observado o menor número de pessoas com nível superior $(35,14 \%)$ e o maior com ensino médio $(64,86 \%)$. Na primavera, o público foi caracterizado com o maior nível superior $(65,22 \%)$ e, juntamente com o verão, apresentou o menor conhecimento sobre a unidade de conservação.

Palavras chave: Ecossistemas de restinga, área protegida, uso público, Praia de Grumari

\section{ABSTRACT}

This study aimed to characterize the profile of visitors of Grumari beach between August 2015 and July 2016. It was possible to identify the level of perception of users on the beach, as well as their preferences and options. For a more accurate analysis, the data were segmented by seasons. This way, it was possible to particularize the profile of visitors seasonally. In general, the public seemed to be regular because $43 \%$ of it go to the beach more than ten times a year, they are educated and they are from west zone of the city $(67.50 \%)$. The visitors seemed to have superficial awareness that the beach was in a conservation unit (48.50\%), the mean stay time was between 2 and 6 hours, and the groups were mainly

\footnotetext{
${ }^{1}$ Graduado em Geografia pela Universidade Federal Fluminense - UFF. E-mail: aurelioperroni@ hotmail.com

${ }^{2}$ Docente do Departamento de Geografia da UFF. E-mail: ritamontezuma@id.uff.br

${ }^{3}$ Coordenadora de Projetos da Empresa de Consultoria Ambiental ECP. E-mail: tartbr@yahoo.com.br
} 
composed of 2 to 4 people (75\%). The main activity chosen by them was the sea bath $(53 \%)$ because the beach was considered the most attractive point. The public showed itself indifferent or little informed about the problems found on the beach $(38 \%)$, the understanding about the importance of sandbank to the beach was characterized as superficial (40\%). In the summer, it was verified that the visitors are little informed, regionally decentralized, with the largest number of people visiting the beach for the first time and the with the largest groups. In the autumn, the public showed more knowledge about the importance of sandbank and it is more assiduous and it is in that season that people go to the beach by themselves and the one who asked for more safety. In the winter, it was observed the lowest number of people with a higher education $(35.14 \%)$ and the highest number with high school education $(64,86 \%)$. In the spring, the public was characterized with the highest education level (65.22\%) and, with summer, it presented the least knowledge level about the protected area.

Key words: Coastal plain ecosystem, protected area, public use, Grumari beach

\section{INTRODUÇÃO}

A visitação em Unidades de Conservação (UCs) tem aumentado devido à popularidade do turismo de natureza e ecológico, portanto, existe a necessidade de conciliar o uso público com a preservação da biodiversidade e demais recursos naturais nos espaços ambientais. Isso não significa restringir a visitação, mas sim possuir um planejamento para minimização dos efeitos negativos da visitação (LEUZINGER, 2010).

O termo uso público é definido como o usufruto gozado pela população, com objetivos recreacionistas, educacionais, científicos ou religiosos (MAGRO, 1999). Esse termo é utilizado para caracterizar as atividades exercidas nas UCs, desde que essas pessoas utilizem de modo indireto naquelas de proteção integral e de modo consciente nas de uso sustentável.

O plano de manejo para essas áreas é fundamental, pois permite que se delimite o zoneamento adequado, em que serão estabelecidas as áreas que podem ou não serem visitadas, a fim de preservar a biodiversidade (LEUZINGER, 2010). Esta constatação é essencial, pois tendo um estudo de uso público da UC, o plano de manejo da respectiva área torna-se mais eficiente em sua implementação.

As UCs são divididas em dois grupos principais: Unidades de Conservação de Proteção Integral e Unidade de Conservação de Uso Sustentável. As primeiras precisam de maiores cuidados e permite o mínimo de intervenção humana, já a segunda os recursos naturais podem ser utilizados de forma direta e sustentável (MMA, 2011).

A praia de Grumari está localizada no bairro de mesmo nome, na Região Metropolitana do município do Rio de Janeiro, com uma área total de. 804,73 hectares (Figura 1). A APA de Grumari possui áreas sobrepostas ao Parque Estadual da Pedra Branca (acima da cota $100 \mathrm{~m}$ de altitude) e à APA do Maciço da Pedra Branca (acima da cota 300m), também possui limite com o Parque Natural Municipal da Prainha - PNMP (FUNBIO; SMAC, 2012).

O trabalho tem por objetivo caracterizar o perfil dos visitantes da praia de Grumari, durante o período de agosto de 2015 a julho de 2016. Em seus objetivos específicos visa 
avaliar o conhecimento dos usuários sobre a importância da UC, identificar as práticas e usos desses visitantes e compreender se existem variações sazonais do público.

Esses dados podem ajudar a identificar se ocorreu variação do uso público ao longo do ano, principalmente nas diferentes estações. Caracterizar essa variação é importante, pois assim, é possível propor sugestões específicas para cada período específico.

Figura 1- Localização e foto da Praia de Grumari, RJ
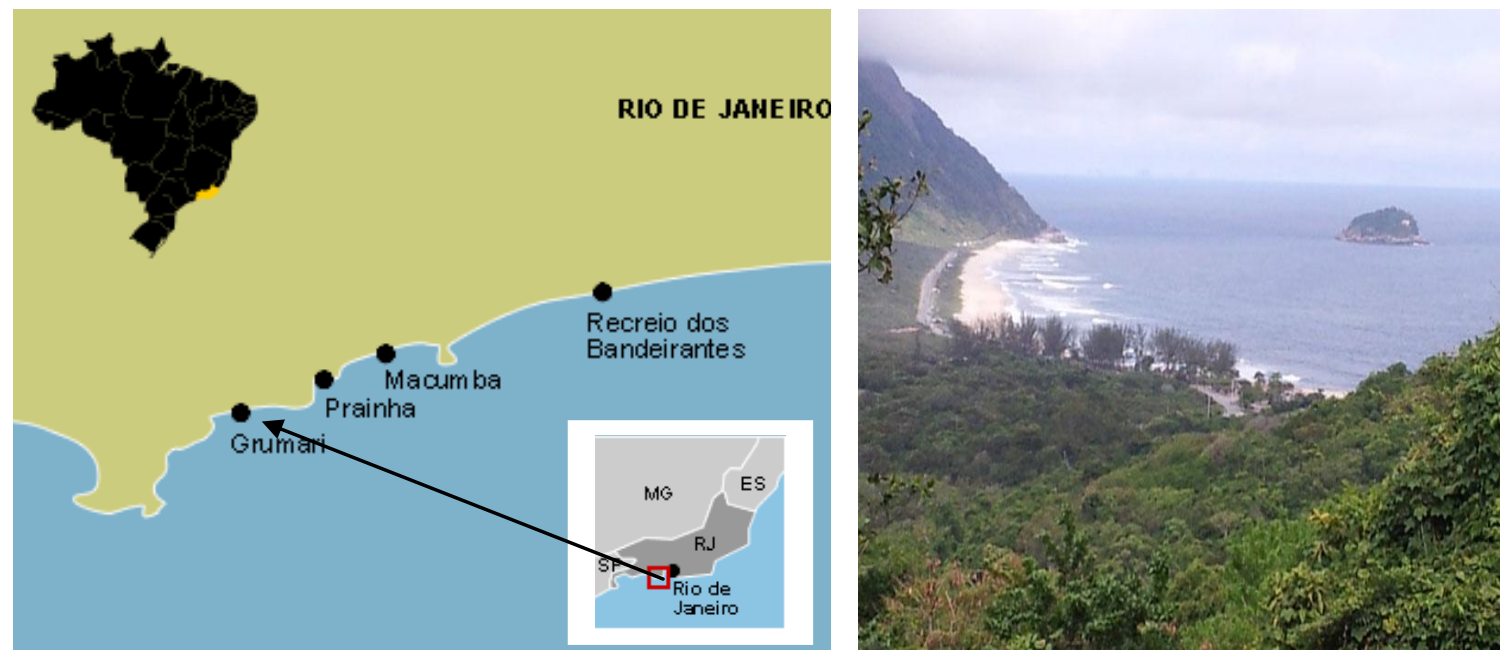

Fonte: http://www.oriodejaneiro.net/grumari.htm

A caracterização do perfil dos visitantes é a principal estratégia para melhor conhecer e satisfazer as necessidades dos usuários. Ao mesmo tempo é possível desenvolver programas preventivos destinados aos visitantes, a fim de que suas atividades produzam o mínimo impacto possível sobre os ambientes naturais e culturais (FREITAS, MAGALHÃES e SANTOS, 2002).

\section{MATERIAL E MÉTODOS}

A metodologia realizada para caracterizar o uso público da Praia de Grumari, baseouse em questionários sobre o perfil do visitante, composto de doze questões múltipla escolha, com um campo para eventuais observações. A metodologia utilizada foi baseada em Takahashi (1998), Freitas, Magalhães e Santos (2002) e Barros (2003), adaptadas para que atendessem aos objetivos deste trabalho.

Como método de obter informações foi utilizado um questionário, o qual foi aplicado ao público da praia. Segundo Gil (2008), o questionário é uma técnica de investigação composta por um conjunto de questões que são submetidas às pessoas com o propósito de obter informações. $\mathrm{O}$ autor ainda explica que construir um questionário consiste basicamente em traduzir objetivos da pesquisa em questões específicas.

As variáveis abordadas no questionário sobre o perfil do visitante foram: gênero; idade; grau de instrução e local de procedência. As questões tratadas na entrevista 
semiestruturada foram: nível de conhecimento sobre a UC; nível de conhecimento sobre a importância da restinga; frequência anual de visitas; tempo de permanência; principais atividades praticadas na praia; principal atrativo da praia; tamanho dos grupos e sugestões ou críticas para a praia.

As entrevistas foram realizadas mensalmente ao longo de toda a orla da praia de Grumari no período de agosto de 2015 até julho de 2016, foram entrevistadas pessoas acima de 16 anos e apenas um indivíduo por grupo participativo.

Todos os questionários foram preenchidos pelo entrevistador, pois em algumas questões foi preciso que se abordasse melhor o tema da questão com o entrevistado. Esse procedimento foi necessário para se certificar do nível de conhecimento do abordado, as principais questões foram: se ele sabia que Grumari é uma UC, portanto, regida por uma legislação específica; a outra foi para entender se o usuário sabia o que era a vegetação de restinga e a sua importância.

Para a análise e interpretação dos dados foi utilizado o software Microsoft Excel, pois com ele foi possível criar tabelas e gráficos, facilitando assim a organização e compreensão das informações adquiridas.

\section{RESULTADOS E DISCUSSÃO}

\section{Gênero e faixa etária}

Dos questionários aplicados, 53,5\% foram respondidos por homens, portanto, as mulheres representaram $46,5 \%$ deste total de participantes. Vale ressaltar que o entrevistador fez abordagens aleatórias, quando um grupo era abordado pedia-se para que apenas um representante participasse da pesquisa, em sua grande maioria indicavam o homem para participar.

O questionário foi respondido majoritariamente por adultos, principalmente na faixa etária de 31 a 40 anos (40,0\%). A classe etária que ocupou o segundo lugar foi a de 21 a 30 anos $(32,0 \%)$. Na avaliação por estações do ano foi identificada que a classe de 31 a 40 anos também se destacou, principalmente, nas estações do verão, outono e inverno.

\section{Grau de instrução}

O nível educacional foi de médio para alto, pois $51,0 \%$ das pessoas possuem nível médio seguido de $47,5 \%$ com nível superior e apenas $1,5 \%$ dos visitantes, com o nível fundamental. Com este resultado, pode-se inferir que um programa de educação do visitante pode ser bem aceito por esse público, pois possuem um bom nível educacional.

Segundo Barros (2003) o nível de conhecimento do visitante é muito importante, visto que o ajuda a compreender a importância das atitudes e ações de todos nas áreas naturais. Este fato pode contribuir para que um programa de educação do visitante seja bem recebido e aceito pelo público.

A estação do ano que apresentou o maior número de visitantes com nível médio foi o inverno (64,9\%), já o de nível superior foi na primavera com 65,2\%. Os visitantes com nível 
fundamental, em termos quantitativos, foram pouco significativos, o maior índice foi identificado na primavera com $2,2 \%$ dos entrevistados.

Foi constatado em campo que na abordagem em grupo, em alguns casos, os integrantes indicavam para participar do questionário aquele tido como o "inteligente" do grupo. Este é outro fator constatado e que pode interferir no resultado da pesquisa.

\section{$\underline{\text { Procedência }}$}

A procedência predominante foi da zona oeste da cidade com $67,5 \%$ dos entrevistados, em segundo lugar a zona sul com $14,5 \%$, seguido pela zona norte com $8 \%$, já as pessoas de outro município representaram $4,0 \%$ e apenas $1,5 \%$ são do centro. Foi registrado que $4,5 \%$ são oriundos de outros estados, os estrangeiros não participaram da pesquisa por falta de compreensão da língua, mas é importante ressaltar que foram identificados ao longo da pesquisa.

Muito provavelmente esse alto índice de visitantes oriundos da zona oeste do Rio de Janeiro se deve à proximidade, pois o deslocamento é um dos motivos que se considera ao realizar um passeio à praia.

Conforme observado por Pereira (2012) a porção oeste da praia de Grumari é frequentado por banhistas da zona oeste da cidade do Rio de Janeiro, já o no centro e extremo leste se concentram os visitantes oriundos da Zona Sul e turistas. O presente trabalho também observou os mesmos resultados destacados pelo autor.

Isto ocorre por causa do acesso, pois para os visitantes da zona sul da zona sul o acesso mais rápido a praia é pela AV. Estado da Guanabara, logo entram pela porção sul da praia. Os visitantes oriundos da zona oeste (com exceção de alguns bairros) tem como acesso mais rápido a Estrada de Grumari, localizada na porção oeste da praia.

$\mathrm{Na}$ avaliação realizada por estações do ano foi possível perceber que a zona oeste se manteve como a principal região de procedência em todas elas, porém no verão foi observado um maior crescimento de outras regiões, principalmente, da zona sul carioca. Na primavera também foi observado o mesmo padrão, mas a zona norte $(17,4 \%)$ fica um pouco a frente da zona sul $(15,2 \%)$. Nestas mesmas duas estações se constataram um aumento do número de turistas (outro município ou estado).

Nas estações do outono e inverno, foi identificado que a maior parte do público é oriunda da zona oeste e com pequena participação da zona sul. Portanto, nesta época do ano a praia de Grumari é frequentada, majoritariamente, por moradores do entorno.

\section{$\underline{\text { Nível de conhecimento sobre a praia e a Unidade de Conservação }}$}

Os visitantes também foram interrogados se eles possuíam conhecimento que a praia estava localizada em uma UC e, portanto, regida por uma legislação ambiental específica. De acordo com os resultados, a maior parte possui o nível de conhecimento superficial $(48,5 \%)$, 
aquelas que em algum momento ouviram que a praia se localiza em uma UC, mas não tem certeza disso.

As pessoas que possuíam o pleno conhecimento, ou seja, sabe o que é uma UC e que a praia se localiza na mesma, representou $41,5 \%$. Isto demonstra que uma grande parte dos visitantes possui conhecimento que a praia se localiza numa UC.

Alguns visitantes sabiam o que é uma UC, porém não tinham o conhecimento que a praia de Grumari faz parte da mesma, estes representaram 3,5\%. Os outros 6,5\% dos entrevistados não sabiam o que é uma UC, sendo eles de nível fundamental e médio com procedência da zona norte e sul da cidade.

Na intepretação por estações do ano, pode-se verificar que no verão e na primavera se registrou os maiores índices de pessoas que não sabiam o que era uma UC. Nestas mesmas estações, foi identificado o menor índice de pessoas com o pleno conhecimento (Aproximadamente 29,0\% em cada).

$\mathrm{O}$ verão registrou o maior indicativo de pessoas que conheciam superficialmente $(59,4 \%)$. A causa mais evidente é que o público dessa estação é muito descentralizado regionalmente, sendo assim, vai à praia somente neste período do ano e não possui qualquer tipo de vínculo com o lugar. Estas pessoas visitam a praia apenas para o banho de mar, e não procuram saber mais informações sobre a área. Os maiores índices de pessoas que possuíam o pleno conhecimento foram identificados no outono $(58,3 \%)$ e inverno $(59,5 \%)$.

\section{Importância da restinga}

Os visitantes, quando indagados se conheciam a vegetação de restinga e se tinham conhecimento de sua importância para o meio ambiente 40,0\% responderam conhecer superficialmente, ou seja, conhecem o tipo de vegetação, mas não tem muita noção de sua importância. Outros 33,0\% disseram ter pleno conhecimento, portanto, sabiam da importância dessa vegetação para a praia. As pessoas que não conheciam esse tipo de vegetação e a caracterizavam como um simples "mato" representaram $27,0 \%$.

Isto evidencia que a maior parte dos visitantes conhece o principal tipo de vegetação que compõe a flora desta praia, entretanto, a conservação da restinga não é muito bem assimilada pelo grande público. Foi verificado em campo que as pessoas não descartam o lixo de modo adequado, pois foi observada uma grande quantidade do mesmo espalhado pela areia e na restinga, principalmente durante o verão.

O período do outono registrou o maior índice de pessoas com o pleno conhecimento $(45,8 \%)$, bem como os que conheciam superficialmente (50,0\%). Apesar da primavera e verão ter identificado o maior número de pessoas que não conheciam esta vegetação $(34,8 \%$ em cada uma), a estação do inverno também teve números bem próximos com 32,6\%. 


\section{Frequência de visitação}

A pesquisa mostrou que a maior parte dos visitantes são frequentadores da Praia de Grumari, pois 43,0\% visitam a mesma mais de dez vezes por ano. Os que disseram frequentar de quatro a dez vezes por ano somaram $26,0 \%$, já os que visitam até três vezes por ano foi $18,5 \%$. Apenas $12,5 \%$ disseram ser sua primeira vez na praia, sendo a maioria turista.

Barros (2003) observou em seu estudo no Planalto do Parque Nacional do Itatiaia, que um fato do visitante realizar várias visitas ao Parque não contribuiu para o seu aprendizado. Isto ocorreu porque a área do Planalto está pouco preparada para receber visitantes, pois não possui trilhas interpretativas, centros de visitantes, painéis educativos, funcionários treinados e um programa de educação dos visitantes implantado.

O mesmo fato pode ser observado na praia de Grumari, já que 43,0\% das pessoas visitam a praia mais de dez vezes ao ano e mesmo com isso, o número de visitantes que possuíam o conhecimento superficial que praia está inserida em uma UC totalizou 48,5\%. Neste caso, uma medida de informação do visitante seria o ideal.

No período do verão foi possível perceber o maior índice de pessoas que visitavam a praia pela sua primeira vez $(25,4 \%)$, já os maiores índices de frequentadores assíduos (mais de dez vezes por ano) foram observados no outono $(52,1 \%)$ e inverno $(48,7 \%)$. Isso só confirma que durante o outono e inverno as pessoas que visitam a praia são aquelas de bairros próximos e com maior informação sobre a UC.

\section{$\underline{\text { Tempo de permanência }}$}

A pesquisa evidenciou que o tempo de permanência predominante na praia foi de 2 a 4 horas $(36,0 \%)$ e de 4 a 6 horas $(37,0 \%)$, a maior parte dos visitantes preferem a permanência de média à prolongada devido ao acesso, pois na maioria das vezes encontram dificuldades ao procurar vagas para estacionar, além que a grande maioria se encontra em um momento de lazer. Acredita-se que por esse mesmo motivo, o número de pessoas que realizam uma visita curta a praia (até 2 horas) foi baixo, representou apenas 5,0\% dos entrevistados. Os que preferem ficar na praia por um tempo ainda maior (acima de 6 horas) representaram 22,0\%.

Segundo Kinker (1999 apud BARROS, 2003), a comparação do tempo de permanência dos visitantes em três Parques Nacionais brasileiros mostrou que esse tempo é diretamente proporcional ao número de atrativos e atividades disponíveis, bem como o grau de liberdade que o visitante tem para se movimentar pela área. Como elencado nas opções do questionário, a praia de Grumari dispõe de diversas atividades que podem ser exercidas, bem como seus atrativos. Por este motivo o tempo médio de permanência na praia foi de 2 à 6 horas.

Realizando uma análise comparativa entre as estações, o tempo de permanência de 6 horas ou mais teve o maior índice registrado no verão com $26,1 \%$, muito provavelmente por causa do sol forte e do horário de verão os visitantes prorrogam sua estada na praia.

Curiosamente, foi observado que no inverno obteve-se o menor índice do tempo de permanência até 2 horas, o qual representou 2,7\%. Esperava-se que durante essa época do ano 
o tempo de permanecia curto de até 2 horas tivesse seu maior pico, devido a temperatura não muito favorável. O inverno também registrou o maior índice de 2 à 4 horas com 46,0\% dos entrevistados.

\section{$\underline{\text { Atividades praticadas na praia }}$}

Conforme o esperado, a principal atividade escolhida pelos visitantes foi o banho de mar com $53,0 \%$, seguido por descanso com $18,5 \%$ e esporte com $11,0 \%$. Dentre os esportes mais praticados se destacam o surf e o futebol.

As pessoas que disseram ir à praia apenas para a contemplação da natureza representou $9,0 \%$, fotografia somou $6,5 \%$. A opção outras atividades somou 2,0\%, este percentual foi totalmente preenchido pela pesca. É importante ressaltar que no extremo oeste da praia foi observado uma concentração de pescadores.

No verão a principal atividade praticada pelos visitantes foi o banho de mar $(73,9 \%)$. Como observado anteriormente, o maior tempo de permanência também foi registrado nesta estação, portanto, pode-se inferir que o público estende esse tempo para praticar o banho de mar, já que a temperatura é muito favorável. Na primavera a principal atividade praticada foi o descanso com $67,4 \%$ dos entrevistados.

No outono, o descanso e banho de mar obtiveram os mesmos resultados, com 29,2\% cada um. No inverno, a principal atividade eleita foi o banho de mar (27,0\%), seguido de descanso $(24,3 \%)$, entretanto, foi o único que registrou fotografia $(21,6 \%)$. É claro que esta última atividade também é exercida em outras estações, mas talvez ela seja praticada com maior frequência no inverno porque a praia se encontra mais vazia.

Este fato evidencia que neste período, as pessoas visitam a praia mais para uma apreciação e relaxamento, diferentemente do verão e primavera onde o principal objetivo é o banho de mar.

\section{$\underline{\text { Atrativos }}$}

A principal atração escolhida foi a praia $(35,5 \%)$ e em segundo lugar, o sossego (31,5\%). Esta reduzida diferença pode ser explicada, pois Grumari quando comparada a outras praias da cidade do Rio de Janeiro, é bem menos cheia devido ao acesso ser somente por veículo particular, além de possuir vagas limitadas para estacionar. Pode-se acrescentar ainda a sua grande beleza cênica. O terceiro atrativo escolhido foi a paisagem $(15,0 \%)$, seguido pelo espaço livre $(10,5 \%)$ e vegetação $(7,5 \%)$.

O principal atrativo no verão foi a praia $(50,7 \%)$, enquanto no inverno e primavera foi o descanso com $56,8 \%$ e $45,7 \%$, respectivamente. O índice mais alto foi registrado no inverno, pois além da temperatura não estar favorável, a praia também está vazia, o que possibilita o relaxamento. No outono ouve um equilíbrio entre as duas opções, com $31,3 \%$ em cada uma. 


\section{$\underline{\text { Tamanho dos grupos }}$}

Os visitantes quando indagados se estavam sozinhos ou acompanhados, 75,0\% responderam estar acompanhados por 2 a 4 pessoas, outros 19,0\% estavam acompanhados de 5 a 10 pessoas, sozinhos foram $4,5 \%$ e apenas $1,5 \%$ estavam com grupos acima de 10 pessoas. Este resultado pode ser um reflexo da forma de acesso, em razão que para se chegar à praia é preciso de um automóvel, desse modo as pessoas se reúnem em grupos para realizar a visita.

$\mathrm{Na}$ avaliação feita por estações do ano se pode constatar que os tamanhos dos grupos não variaram muito, mantendo a média de 2 a 4 pessoas. Apenas no verão foi possível perceber que ouve um aumento do tamanho dos grupos de 5 a 10 pessoas, os quais representaram $39,1 \%$, enquanto o de 2 a 4 correspondeu a 55,1\%. Certamente o tamanho dos grupos aumentou no verão por se tratar de um período de alta temporada.

\section{$\underline{\text { Sugestões ou críticas para a praia }}$}

Nesta questão, a maior parte dos usuários disse não ter nada a declarar (20,5\%), outros 17,5\% afirmaram que está bom desse jeito, ou seja, 38,0\% dos frequentadores não conseguem identificar os principais problemas encontrados na praia ou atribuir alguma sugestão.

A falta de segurança na praia foi bem criticada por parte dos visitantes, principalmente no período da noite, ao todo representaram 18,0\%. Em relação ao lixo, $16,5 \%$ dos entrevistados disseram que a praia possui uma grande quantidade do mesmo. Os que pediram mais sinalização com informações representaram 7,5\%.

As sugestões e críticas somaram 20,0\%, sendo a iluminação o principal serviço solicitado pelos visitantes, seguido da instalação de banheiros. As outras sugestões e críticas foram as seguintes: controlar melhor o acesso; ampliar o estacionamento; disponibilizar mais salva vidas; ampliar o comércio; melhorar a preservação da natureza; melhorar o acesso a praia; melhorar os quiosques; ampliar o envolvimento comunitário; implantar acessibilidade para deficientes físicos; falta de infraestrutura; falta de organização; banhistas mal conscientizados.

Foi constatado que o público da primavera e, principalmente do verão são os menos críticos, pois as opções: está bom desse jeito e nada a declarar foram as mais votadas. Justamente foi nestas estações que se percebeu a maior descentralização regional do público, com destaque para a zona sul (no verão) e zona norte (na primavera).

A estação da primavera foi a que obteve o maior índice de nível superior, portanto, possuir um alto grau de escolaridade não necessariamente está relacionado em ter conhecimento sobre a área ou até mesmo sobre as regras de uma UC. Pode-se inferir que, neste caso, o fator que causa essa ausência de conhecimento sobre a área de estudo é a região de procedência, pois esses visitantes possuem elevado grau de instrução, mas são de regiões distantes da UC. Os dados sobre frequência de visitação também confirmam essa hipótese, 
pois este público é o que menos visita a praia ao longo do ano, ficam restritos ao período de alta temporada.

Nas estações do outono e inverno, os visitantes pediram por mais segurança $(31,3 \%$ e $28,6 \%$, respectivamente) e elencaram muitas críticas à praia.

As estações outono e inverno obtiveram os maiores índices de frequência anual de visitas, assim como, a procedência predominante foi a zona oeste. O inverno foi a estação que obteve o maior número de pessoas com nível médio (64,9\%), desse modo, constata o que foi mencionado anteriormente, que a região de procedência possui maior influencia do que o nível de escolaridade quando se refere a conhecimento sobre a área.

\section{CONCLUSÃO}

O trabalho possibilitou a definição de alguns indicadores, o que permite aos gestores priorizar suas áreas de atuação. Demonstrou que a falta de consciência dos visitantes em relação aos objetivos da unidade de conservação, foi maior durante o verão.

Foi possível identificar que o Parque, pelo menos na praia de Grumari, não tem cumprido de modo satisfatório um dos objetivos elencados pelo SNUC, o de favorecer condições e promover a educação e interpretação ambiental, já que não dispõe de um modo eficiente de informação dos visitantes.

De acordo com os dados obtidos, o público da praia de Grumari pode ser caracterizado, majoritariamente, como adulto (faixa etária de 21 à 40 anos), com a escolaridade variando de médio à superior e procedente da Zona Oeste da cidade. Em sua maior parte, os visitantes possuem uma compreensão superficial que a praia está inserida em um Parque $(48,5 \%)$, o mesmo nível de conhecimento pode ser dito sobre a importância da restinga $(40,0 \%)$.

O público apresentou uma frequência média de visitação, pois 40,0\% realizam a visita mais de dez vezes ao ano. $O$ tempo de permanência varia de 2 à 6 horas, tendo como principal atividade o banho de mar. Os grupos se caracterizam ser composto de 2 a 4 pessoas.

\section{REFERÊNCIAS}

BARROS, Maria Isabel Amando de. Caracterização da visitação, dos visitantes e avaliação dos impactos ecológicos e recreativos do planalto do Parque Nacional do Itatiaia. 2003. 135 p. Dissertação (Mestrado) - Escola Superior de Agricultura Luiz de Queiroz - Universidade de São Paulo.

FUNBIO (Fundo Brasileiro para a Diversidade); SMAC (Secretaria de meio Ambiente da cidade do Rio de Janeiro). Plano de Manejo do Parque Natural Municipal da Prainha e Parque Natural Municipal de Grumari. Rio de Janeiro - RJ, 2012.

FREITAS, Welington Kiffer de; MAGALHÃES, Luis Mauro Sampaio; SANTOS, Maísa Guapyassú dos. Potencial de uso público do Parque Nacional da Tijuca. Acta Scientiarum. Technology, v. 24,n 6, p. 1833-1842, 2002. 
GIL, Antônio Carlos. Métodos e Técnicas de Pesquisa Social. $6^{\circ}$ ed. São Paulo: Editora Atlas S.A. 2008.

LEUZINGER, M. D. Uso Público em Unidades de Conservação. Congresso de Direito Ambiental da PUC-RIO, 2010, Rio de Janeiro. Disponível em: <http://www.nima.pucrio.br/aprodab/artigos/uso_publico_em_unidades_de_conservacao_mar cia_leuzinger.pdf >. Acesso em: 08 de setembro de 2016

MAGRO, Teresa Cristina. Impactos do uso público em uma trilha no Planalto do Parque Nacional do Itatiaia. 1999. 151 p. Tese (Doutorado em Ciências da Engenharia Ambiental) Escola de Engenharia de São Carlos - Universidade de São Paulo, São Carlos - SP.

MMA (Ministério do Meio Ambiente). Resolução $\mathbf{N}^{\mathbf{0}}$ 303, de 20 de março de 2002. CONAMA (Conselho Nacional do Meio Ambiente). Disponível em: <http://www.mma.gov.br/port/conama/res/res02/res30302.html > Acesso em: 12 de janeiro de 2016

PEREIRA, Tiago Ferreira Pinheiro. Conflitos Sócio-Ambientais nos Parques Naturais Municipais da Praina e Grumari - Maciço da Pedra Branca - RJ. Rio de Janeiro, 2012. 359 f. Tese (Doutorado em Geografia) - Departamento de Geografia da Universidade Federal do Rio de Janeiro, 2012.

TAKAHASHI, L.Y. Caracterização dos visitantes, suas preferências e percepções e avaliação dos impactos da visitação pública em duas unidades de conservação do estado do Paraná. Curitiba, 1998. Tese (Doutorado) - Universidade Federal do Paraná. 